ABCDDV/1091

ABCD Arq Bras Cir Dig Letter to the Editor 2015;28(1):87-89

DOI:http://dx.doi.org/10.1590/S0102-67202015000100022

\title{
GASTROINTESTINAL STROMAL TUMOR OF THE RECTUM TREATED WITH NEOADJUVANT IMATINIB FOLLOWED BY TRANSANAL ENDOSCOPIC MICROSURGERY
}

\author{
Tumor gastrointestinal estromal de reto tratado com \\ imitanib neoadjuvante seguido de microcirurgia \\ endoscópica transanal
}

Caio Sergio Rizkallah NAHAS, Sergio Carlos NAHAS, Carlos Frederico Sparapan MARQUES, Rafael SCHMERLING, Leonardo Alfonso BUSTAMANTE-LOPEZ, Ulysses RIBEIRO JUNIOR, Ivan CECCONELLO

From the Department of Gastroenterology, Surgical Division, Clinic Hospital, School of Medicine, University of São Paulo, São Paulo, Brazil.

\section{Correspondence:}

E-mail: caionahas@uol.com.br
Caio Sergio Rizkallah Nahas

Financial source: none Conflicts of interest: none

Received for publication: 05/12/2013 Accepted for publication: 25/11/2014

\section{INTRODUCTION}

$\square$ he gastrointestinal stromal tumor (GIST) is a rare type of tumor that expresses CD117 oncogene that can be detected by immunohistochemistry ${ }^{2}$ The most common sites of GISTs are stomach (70\%), and small intestine (20\%), while rectum is comprised in only $3 \%$ of the cases ${ }^{5}$. Although a rare condition, the GIST located in the distal rectum may require an abdominoperineal resection. There is no data to support the use of Imatinib (Gleevec from Novartis, Basel, Switzerland), a selective inhibitor of tyrosine quinase, as neoadjuvant therapy. However, the last session consensus for the treatment of GIST, suggests that this form of therapy can be used in some cases where anal sphincter is involved ${ }^{7}$. The objective of this report is to describe a case of GIST distal rectum in the rectovaginal septum with partial invasion of the anal sphincter, which was successfully treated by neoadjuvant therapy with imatinib followed by the technique of transanal endoscopic microsurgery (TEM). The results are compared with experience in the literature.

\section{CASE REPORT}

A 63-years-old female patient was sent to the hospital with complaints of mild constipation. A clinical examination did not detect any palpable abdominal mass. Rectal digital exam revealed a $5 \mathrm{~cm}$ mass in the left anterior rectal wall, located $2 \mathrm{~cm}$ above the dentate line. The mass was solid, with a smooth and regular surface. Colonoscopy confirmed the presence of a round and regular mass, covered by normal mucosa, measuring about $5 \mathrm{~cm}$ in diameter, in the left anterior wall. A transrectal biopsy with Tru-cut needle was performed. Immunohistochemical positivity for CD117 and CD34 antigens, and negative for smooth muscle actin or S-100 protein confirmed the diagnosis of a submucosal rectal GIST. The mitotic activity was $2 \times 10$ high power field (HPF), and there was absence of necrosis. Computed tomography showed the presence of a tumor of $5.2 \times 5.0 \times 5.6 \mathrm{~cm}$, irregular, with eccentric thickening of the left anterior rectal wall in the lower rectum, with close contact with the posterior vaginal wall and partial invasion of the levator ani muscle, but with no evidence of lymph node or distant metastases (Figure 1).

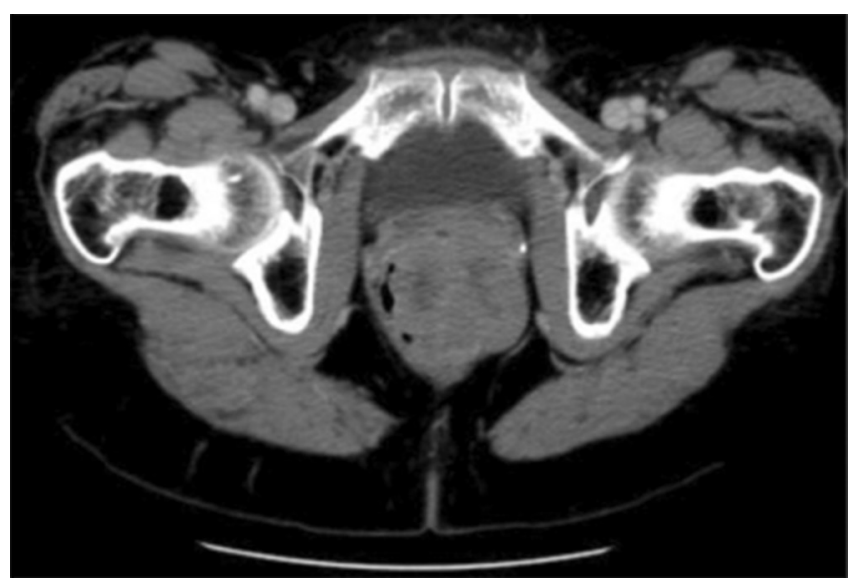

FIGURE 1 - TC showing the presence of a $5.2 \times 5.0 \times 5.6 \mathrm{~cm}$ mass with a marked, irregular, eccentric thickening of the left anterior rectal wall of the lower third of the rectum, with close contact with the posterior vaginal wall and partial invasion of the levator ani muscle.

As curative surgery would have implied abdominoperineal resection with permanent colostomy, treatment with Imatinib at a standard dose (400 mg/day) was started. Response to treatment was evaluated using CT every three months. Maximal response was obtained at six months, which was maintained after eight months of treatment. At that time, a pelvic MRI showed a partial diminution of the mass dimensions $(4.0 \times 3.0 \times 3.1 \mathrm{~cm})$, but still occupying the rectovaginal septum, with close contact of the cranial portion of levator ani muscle (Figure 2).

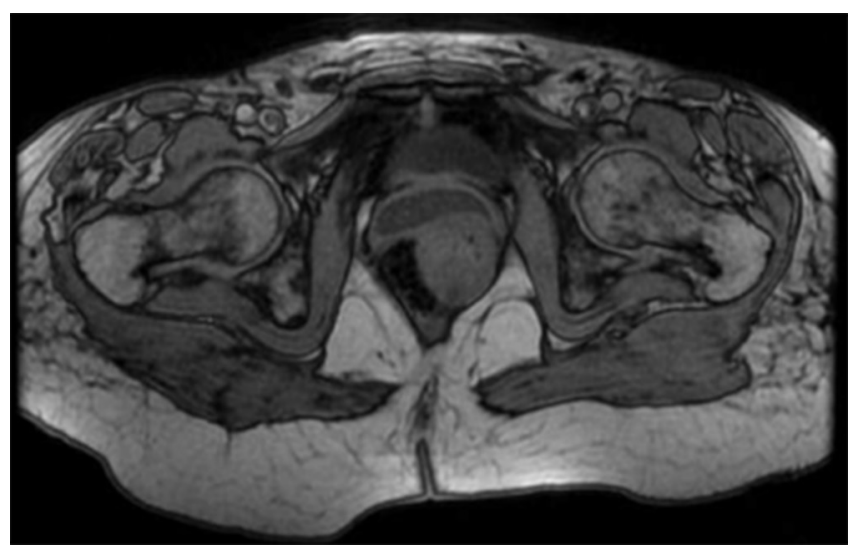

FIGURE 2 - Assessment of tumour response to Imatinib: MRI showing a predominantly exophytic, heterogenous, submucosal mass (measuring 4.0×3.0x $3.1 \mathrm{~cm}$ ) on the left anterior rectal wall occupying the rectovaginal septum, with partial invasion of the cranial portion of levator ani muscle.

The partial tumour mass reduction was enough to allow a local excision using the transanal endoscopic microsurgery (TEM) technique. The tumor mass was completely excised enbloc with part of the posterior wall of the vagina and a minimal portion of tissue from the levator ani muscle (Figure 3). 


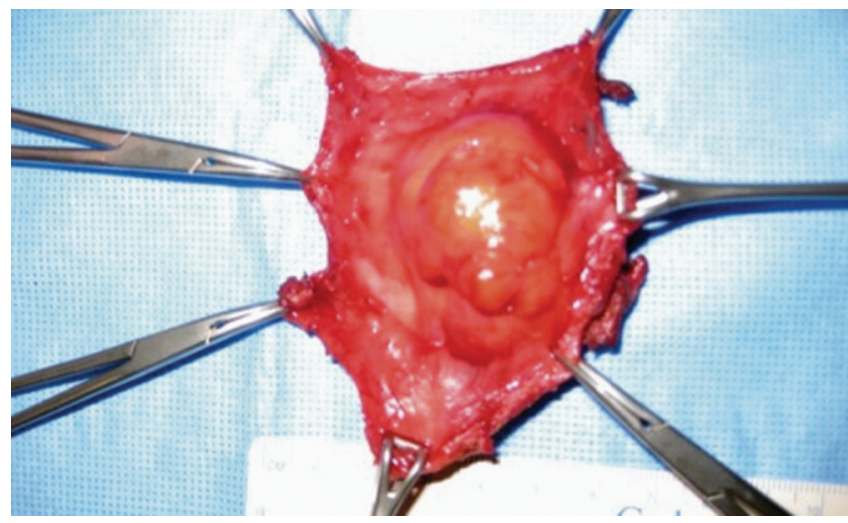

FIGURE 3 - Surgical specimen with tumor mass completely excised en-bloc with part of the posterior wall of the vagina and a minimal portion of tissue from the levator ani muscle

The rectal wall defect was closed primarily. For that, a flap of rectal wall was advanced to the anal verge. The suture consisted of conventional hand-sewn interrupted stitches (Figure 4).

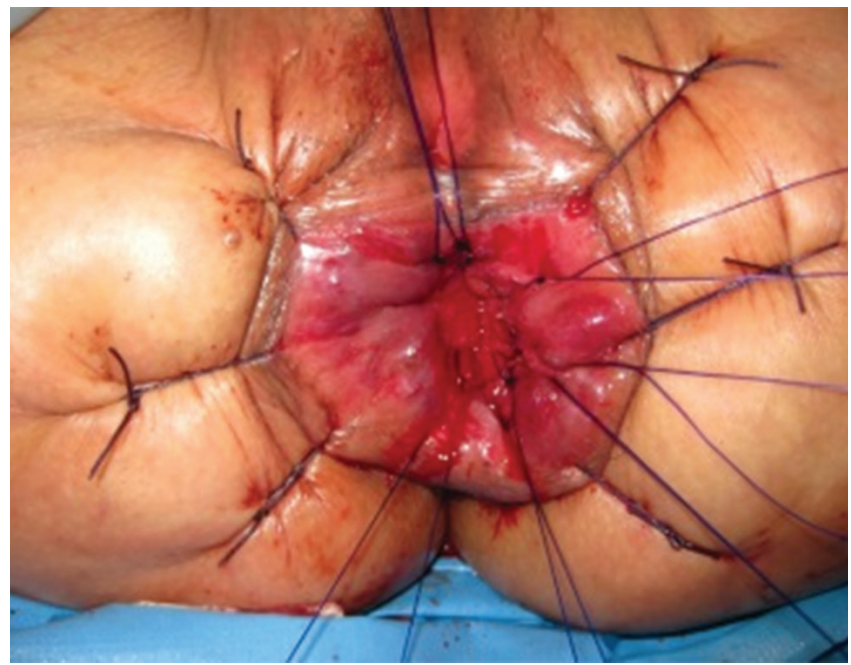

FIGURE 4 - Rectal wall defect closure with conventional handsewn interrupted suture

TEM suturing technique could not be used in this case since it was not possible to keep the gas insufflation at the anal verge (the TEM retoscope could not seal the anus). The vaginal wall was also closed primarily with a transvaginal running suture. A laparoscopic loop ileostomy was created to prevent from rectovaginal fistulae. The postoperative period was uneventful and the patient was sent home on $4^{\text {th }}$ day. The loop ileostomy was taken down four months later and the patient recovered normal defecation with minimal transient fecal incontinence. Pathological analysis of the surgical specimen identified a white firm $3.5 \times 3.0 \times 3.0$ $\mathrm{cm}$ well delimited rectal mass, occupying the muscularis mucosa, submucosa, muscular propria, and the adjacent soft tissue close to the vagina interface. The specimen margins were free of tumor. The lesion expressed CD34 or CD117 and showed no mitotic activity (zero mitoses in $50 \mathrm{HPF}$ ). As for now, the patient presented no evidence of recurrence of disease (follow up period of 46.2 months).

\section{DISCUSSION}

As the incidence of GIST of the rectum is so low, there are only data from few small series and case reports in the PubMed indexed English literature ${ }^{2-10}$. It is generally agreed that complete surgical resection with negative tumor margins is the principal curative procedure for primary and non-metastatic tumors, particularly for those at a low risk ${ }^{2}$. Various surgical procedures may be considered, including conventional transanal local excision ${ }^{5}$, transperineal local excision ${ }^{4}$, abdomino-perineal resection ${ }^{3}$, transacral excision ${ }^{10}$, low anterior resection of the rectum ${ }^{6}$ and TEM ${ }^{1}$. The choice of procedure depends on tumor size and location. Imatinib is reserved for the treatment of patients with advanced GIST, in the adjuvant postoperative treatment of high risk tumors or in cases of incomplete surgical resection. Although further evidence for the efficiency of this drug in the neoadjuvant setting is still needed, it is believed that Imatinib may enhance the resectability of inoperable malignant GIST and may allow for optimal surgical timing, especially when there is intent to spare the anal sphincter in patients with low rectal tumors. The optimal duration of preoperative Imatinib for patients with locally advanced GIST is unknown. The median time to best response in all responding patients was about four months (107 days), and most responses happened in nine months of treatment ${ }^{8}$.

After reviewing the PubMed indexed English literature of the last 10 years, was found 53 cases of patients with rectal GIST treated with neoadjuvant Imatinib ${ }^{2-10}$. The indications for neoadjuvant imatinib were: patients that were initially considered unresectable, or patients that have initial indication for extensive surgery (including anal sphincter resection). In only one of these cases, radiation was added to Imatinib ${ }^{6}$. A sphincter-saving procedure was performed in 42 patients (21 conventional transanal local excision, 16 low anterior resection, four transacral resection, one transperineal local excision, and one TEM). The pathological examination documented a complete pathological response in seven cases.

This case is the second in the literature in which the tumor could be removed by TEM. This technique allowed us to perform a full thickness resection of the rectal wall (combined with en-bloc resection of the posterior vaginal wall), with complete resection of the tumor. The procedure was safe and obeyed the oncologic principles.

Since the incidence of rectal GIST is much lower than that of GIST in the stomach or small intestine, the clinicopathological profiles of rectal GIST have not yet been accurately characterized, and there is therefore the tendency to validate the same prognostic factors for the latter as for such tumors at other sites, particularly gastric GIST. The most important and easily applicable histological criteria for prediction of GIST are its size and mitotic rate. A rate of $\leq$ five mitoses per $50 \mathrm{HPF}$ is commonly used as a limit for a tumor with expected benign behavior, and according to a large study, this can discriminate between benign and malignant tumors, especially gastric GISTs. Tumors of $2 \mathrm{~cm}$ in diameter are generally expected to behave in a benign fashion. Tumors of $<5 \mathrm{~cm}$ in diameter are associated with a better survival rate than those of $5-10 \mathrm{~cm}$ in diameter, which in turn have a better prognosis than those of $>10 \mathrm{~cm}$ in diameter. Degrees of cellularity and atypia have also been suggested as useful criteria, but their reproducibility is more problematic. Based on all these information, was considered the present case as a lowrisk GIST, since the tumor specimen measured less than $5 \mathrm{~cm}$ in diameter and showed no mitotic activity (zero mitoses in 50 HPF). For those reasons was decided not to give adjuvant imatinib. 
1. Arezzo A, Verra M, Morino M. Transanal endoscopic microsurgery after neoadjuvant therapy for rectal GIST. Digestive and Liver Disease 43 (2011) 921- 924.

2. Blay JY, Bonvalot S, Casali P, et al. GIST consensus meeting panellists: Consensus meeting for the management of gastrointestinal stromal tumours. Report of the GIST Consensus Conference of 20-21 March 2004, under the auspices of ESMO. Ann Oncol 2005;16:566-78.

3. Fiore M, Palassini E, Fumagalli E, Pilotti S, Tamborini E, Stacchiotti S, Pennacchioli E, Casali PG, Gronchi A. Preoperative imatinib mesylate for unresectable or locally advanced primary gastrointestinal stromal tumors (GIST). Eur J Surg Oncol. 2009 Jul;35(7):739-45. Epub 2008 Dec 24

4. Hamada M, Ozaki K, Horimi T, Tsuji A, Nasu Y, Iwata J, Nagata Y. Recurrent rectal GIST resected successfully after preoperative chemotherapy with imatinib mesylate Int J Clin Oncol (2008) 13:355-360.

5. Lo SS, Papachristou GI, Finkelstein SD, Conroy WP, Schraut WH Ramanathan RK. Neoadjuvant imatinib in gastrointestinal stromal tumor of the rectum: report of a case. Dis Colon Rectum 2005;48:1316-1319.

6. Machlenkin S, Pinsk I, Tulchinsky H et al (2011) The effective of neoadjuvant imatinib therapy on outcome and survival after rectal gastrointestinal stromal tumour. Colon Dis 13:1110-1115.

7. Mandalà M, Pezzica E, Tamborini E, Guerra U, Lagonigro SM, Forloni B, Barni S. Neoadjuvant imatinib in a locally advanced gastrointestinal stromal tumour (GIST) of the rectum: a rare case of two GISTs within a family without a familial GIST syndrome. Eur J Gastroenterol Hepatol. 2007 Aug;19(8):711-3.

8. Nahas, SC, Nahas, CS, Marques CF, Dias AR, Pollara WM, Cecconello I. Transanal endoscopic microsurgery (TEM): a minimally invasive procedure for treatment of selected rectal neoplasms. $A B C D$, arq. bras. cir. dig. 2010, vol.23, n.1, pp. 35-39.

9. Salazar M, Barata A, André S, Venâncio J, Francisco I, Cravo M, Nobre-Leitão C. First report of a complete pathological response of a pelvic GIST treated with imatinib as neoadjuvant therapy. Gut. 2006 Apr;55(4):585-6.

10. Wang JP, Wang T, Huang MJ, Wang L, Kang L, Wu XJ. The role of neoadjuvant imatinib mesylate therapy in sphincter-preserving procedures for anorectal gastrointestinal stromal tumor. Am J Clin Oncol. 2011 Jun;34(3):314-6.

\section{ABCDDV/1092}

$A B C D$ Arq Bras Cir Dig Letter to the Editor 2015;28(1):89-90

DOI:http://dx.doi.org/10.1590/S0102-67202015000100023

\section{ENDOSCOPIC HEMOSTASIS} OF A BLEEDING GASTRIC GASTROINTESTINAL STROMAL TUMOR (GIST) WITH ENDOLOOP PLACEMENT

Hemostasia endoscópica de tumor estromal gastrointestinal (GIST) gástrico com colocação de "endoloop"

Felipe Alves RETES, Bruno da Costa MARTINS Mauricio Paulin SORBELLO, Cezar Fabiano Manabu SATO Fabio Shiguehissa KAWAGUTI, Fauze MALUF-FILHO Ulysses RIBEIRO-JUNIOR

From the Instituto do Câncer do Estado de São Paulo, Faculdade de Medicina, Universidade de São Paulo (Cancer Institute of São Paulo State Faculty of Medicine, University of São Paulo), São Paulo, SP, Brazil

Financial source: none

Correspondence:

Conflicts of interest: none

Mauricio Paulin Sorbello

E-mail: sorbello.maunicio@gmail.com
Received for publication: 21/01/2014

Accepted for publication: 09/12/2014 astrointestinal bleeding due to gastric
neoplasia is difficult to manage and may
provoke dramatic situations. For the most part, therapeutic endoscopic methods provide only temporary success in controlling bleeding. Often, a poor clinical condition and an advanced stage of the neoplastic disease mean these patients will receive exclusively palliative clinical care. Hence, surgical procedures are often contraindicated, either due to lack of clinical conditions or the increased mortality resulting from surgical trauma. In such cases, alternative endoscopic techniques have been described as minimally invasive means of controlling tumor-induced bleeding.

\section{CASE REPORT}

A 79 year-old man with gastric GIST, receiving Imatinib for the presence of multiple hepatic (Figure 1), pulmonary and bone metastases, was admitted to the Cancer Institute of the University of São Paulo Medical School,São Paulo, SP, Brazil after presenting massive hematemesis, followed by syncope.

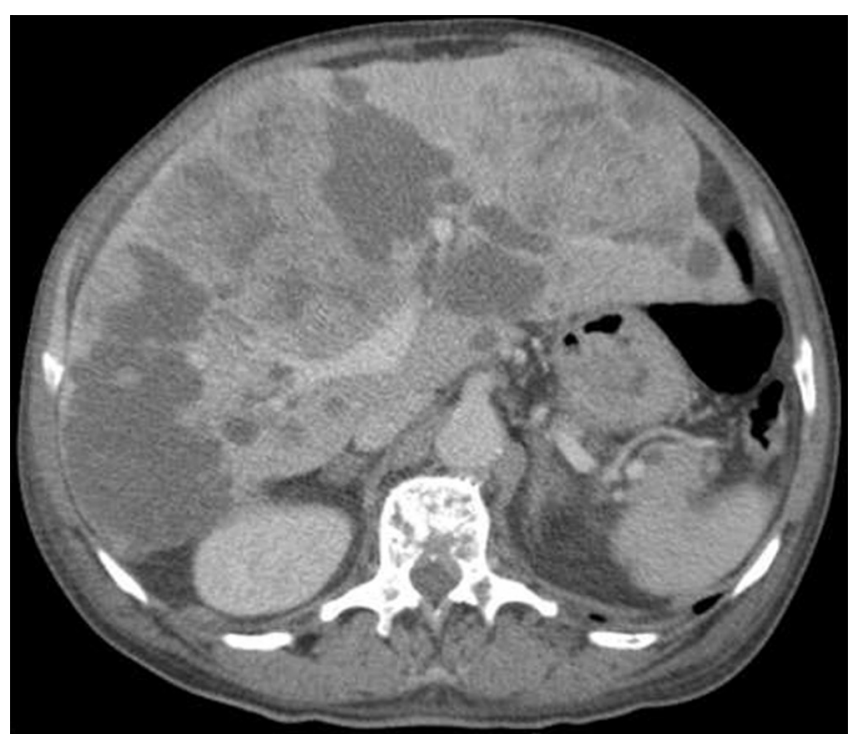

FIGURE 1 - Multiple hepatic metastases

An upper gastrointestinal endoscopy was indicated. The exam revealed fresh blood in the gastric chamber and a $4 \mathrm{~cm}$ submucosal ulcerated lesion, partially covered with adherent clots in the cardia region. Since there was no ongoing bleeding, endoscopic therapy was not performed at that time. However, after multidisciplinary discussion, it was decided to attempt endoscopic hemostasis due to the high risk involved in using anesthesia to perform surgical resection. An endoloop was placed at the base of the lesion in a retroflexed position (Figure 2).

One week later, an endoscopic review exam was performed, demonstrating the successful hemostastic procedure (Figure 3 ).

The patient was then referred to and followed by the palliative care group and died two months later, without further bleeding. 